\title{
CALIDAD DE VIDA, ENFERMEDAD Y HOSPITALIZACIÓN
}

\section{QUALITY OF LIFE, ILLNESS AND HOSPITALIZATION}

\author{
Recibido: 13/04/2015 Revisado: 30/04/2015 Aceptado: 15/06/2015 \\ María del Mar Alfaya Góngora'
}

En sociedades avanzadas, el concepto de calidad de vida se presenta como un valor y un indicador de prosperidad y bienestar; una meta conseguida y siempre mejorable. Pero definir el concepto de calidad de vida es algo complejo, ya que es utilizado en diversos contextos y en ocasiones con significados diferentes. Además es un concepto relativo, ya que tiene que ver con la valoración que la persona haga sobre sí misma y por tanto pertenece al campo de la subjetividad, aunque se relaciona con el mapa de la objetividad que rodea a cada individuo.

La OMS propuso, la siguiente definición: "Percepción personal de un individuo de su situación en la vida, dentro del contexto cultural y de valores en que vive, y en relación con sus objetivos, expectativas, valores e intereses" (OMS citada por Mones, 2004). Por ello, evaluar la calidad de vida, debe responder a enfoques cuantitativos y cualitativitos.

La salud, definida en la Carta Fundacional de la Organización Mundial de la Salud, como aquel "estado de bienestar físico, psíquico y social y no sólo como la ausencia de enfermedad" (OMS, 1948), se nos muestra no solo como un indicador más de la calidad de vida, sino como un determinante, en torno al cual giran los demás factores que puedan influir en esta. En este contexto, la enfermedad se entendería como un proceso biológico, ya que supone una alteración estructural o funcional; un proceso psicológico, pues conlleva sufrimiento; y un proceso social porque supone un estado de incapacidad y menoscabo de la autonomía que repercute en las relaciones y actividades sociales.

Por ello, cada vez cobra mayor relevancia en el ámbito de la salud, el concepto calidad de vida relacionado con la salud (CVRS), concepto complejo y multidimensional que se refiere a la reacción de la persona ante su estado de salud, como la percibe y el impacto que puede ocasionar la enfermedad en el plano físico, psicológico o social (Gill y Feisntein, 1994 y Guyatt, Fenny y Patrick, 1993).

Según López Ibor (2007), enfermar implica afrontar una situación nueva y amenazante. Cuando una persona enferma, experimenta una serie de reacciones emocionales. Los factores que influyen en esas reacciones son diversos, entre ellas la personalidad del paciente, su edad, el tipo de enfermedad, la familia y redes sociales, el hospital y la relación con los profesionales de la salud que le atienden. La hospitalización, también puede desencadenar reacciones distintas en cada individuo, que pueden depender de factores diversos, entre los que cabe destacar: la naturaleza de la enfermedad, personalidad, y su entorno social. No siempre los pacientes interpretan el hospital como medio seguro para solución a sus problemas de salud. En ocasiones, lo ven como un lugar que aumenta su ansiedad, un alejamiento de su entorno habitual y conocido, su hogar, para permanecer en un entorno con un ambiente impersonal, en el que te despojan de tus ropas, tu intimidad, obligado a compartir habitación y adaptarte a una nueva rutina, a horarios de comidas, sueño y visitas; caras nuevas, cada una de ellas con una función concreta que desarrollar.
Cuando la enfermedad obliga a la hospitalización, el paciente es privado de autonomía, se ve sometido a la dependencia de otros y a una serie de circunstancias que pueden agravar su sufrimiento (Gómez Díaz, 2000).

El padecimiento de un dolor o malestar provocado por una enfermedad, puede someter al paciente a una situación de "'sumisión" frente al personal que le trata y cura.

La relación es asimétrica y vertical (Muñoz y Molina, 2004). "El dolor es un instrumento de poder porque nos hace dependientes del médico y sólo él puede interrumpir nuestro sufrimiento", (Le Breton, citado por Allué, 2004).

En nuestro mundo civilizado, donde la vida está marcada por la tecnología y la cultura científico-técnica, los hospitales representan un escenario en donde la técnica forma parte de la rutina como algo "natural", como un medio para conseguir un fin. A mayor complejidad de las unidades o servicios sanitarios, más notable es la tecnología (Gómez Díaz, 2000). Este entorno tecnificado, conocido para los que tienen que hacer un uso profesional de él, proporciona seguridad y recursos que facilitan su actuación, pero en el receptor de estos "beneficios", se dan circunstancias distintas $y$, en ocasiones, opuestas: desconocimiento, inseguridad, incomunicación y aislamiento.

Para Pezo, Costa y Komura (2004), el sufrimiento ocasionado por las emociones negativas derivadas de la enfermedad, podría ser aliviado si el proceso es conocido por los profesionales de la salud. En su investigación de diseño etnográfico, resaltan la importancia de la escucha activa y la observación participante para la recogida de información sobre las manifestaciones verbales y no verbales indicadores de estado depresivo, así como la vivencia comunes a estos pacientes.

Para López Ibor (2007)

Un hospital moderno es la empresa más compleja que existe. Ingresar en uno para recibir cuidados es una experiencia que no deja impasible a nadie. La medicina científico-natural ha transformado edificios e instituciones creados para cuidar y albergar (también a aislar) en lugares de altas complejidad y tecnología, diseñados para tratar físicamente a los pacientes más que a prestar atención a las necesidades psicológicas y a la calidad de vida. Los pacientes experimentan un número importante de reacciones emocionales antes y después de procedimientos médicos, que pueden ser de ansiedad (producida por un miedo al dolor o incertidumbre ante el futuro), o de depresión o problemas de adaptación (según las expectaciones que tuviera cada individuo) o de rebeldía (frente a un destino no deseado). Lo más común es que se tenga miedo a lo desconocido, al dolor, a la posibilidad de tener una enfermedad incurable, a la destrucción del cuerpo o a la pérdida de autonomía o miedo a la muerte.

Los hospitales son instituciones que se nos presentan como pequeños mundos con una identidad propia, como un sistema. Tanto en su estructura externa, como en la funcional, son como microcosmos, con fronteras 
imaginarias que delimitan el interior del exterior y resaltan las peculiaridades de un sistema, en el que las personas que entran en él, desempeñan roles definidos y a veces estereotipados.

En la parte estructural, haciendo una similitud con cualquier núcleo urbano, las unidades de hospitalización son las "zonas residenciales" y se podría decir que el resto (zonas de administración, almacenes, servicios para el diagnóstico y la parte hostelera como cocina, lavandería mantenimiento, etc.), son las "zonas de servicio", dedicadas a abastecer y mantener a "los residentes". Los "residentes" pueden ser internos (el personal sanitario) y externos (los pacientes).

Centrándonos en las "zonas residenciales", cada unidad de hospitalización es un "barrio", con características, estructura y funcionalidad propia. Sus "residentes internos" son los que viven habitualmente allí, conocen el "barrio" y los "barrios vecinos", se conocen entre ellos, se desenvuelven con soltura, conocen el lenguaje y los acontecimientos que allí suceden, el entorno les es conocido.

Los "residentes externos" son personas transitorias, circunstancialmente pasan por allí, y generalmente lo hacen porque no tienen otra alternativa. Por ello, se sienten extraños, dependientes de la hospitalidad que se le ofrezca, y con la sensación de que, el precio para conseguir lo que les obliga a esa estancia temporal, es resignarse, adaptarse y salir lo más pronto y airoso posible. A veces entre ellos se forman grupos solidarios, se transmiten información, se ayudan, se dan ánimo.

Los "residentes internos" los acomodan en pequeños alojamientos, compartidos con otros "residentes externos" (las habitaciones) y les ayudan a cumplir el principal deseo que es solucionar lo mejor y antes posible el problema que les obliga a permanecer allí, alejados de sus entornos, costumbres y grupos de referencia.

Probablemente, conocen muy bien cómo solucionar estos problemas, pero quizás desconocen los sentimientos y emociones que estos conllevan, a los que suman aquellos provocados por el temor y la inseguridad de encontrarse en un entorno extraño y hostil en cuanto a la incertidumbre de la circunstancia (la enfermedad) que les obliga a permanecer en ese lugar (el hospital). O quizás si lo sepan, pero no disponen de "recursos" para abordarlos, o no los consideran un aspecto importante, o no lo incluyen dentro de sus competencias.

El desconocimiento real y profundo de lo que se padece, la inseguridad, el temor al dolor a la muerte o a ver vulnerada su dignidad, la falta de información o una comunicación ineficaz, hacen que se establezca una relación en desigualdad de condiciones, en la que es necesaria acercar posiciones y establecer una actuación transaccional en la que prestadores de servicios y pacientes negocien condiciones.

Estudios como el de Simini (1999), reflejan los efectos que los pacientes recuerdan con más desagrado y que se repiten en diversos entornos socioculturales: ruido insoportable y dificultades para el sueño, sed, dolor insuficientemente aliviado con analgésicos, sufrimiento psicológico derivado de la sensación de soledad y abandono y falta de información sobre los procedimientos que se le van realizando y sobre su situación.

Un ingreso hospitalario, origina impacto emocional y aumenta las distorsiones cognitivas y las respuestas de estrés o depresión. Son situaciones complejas influidas por la causa que motiva el ingreso hospitalario y por procesamiento de la información que el paciente puede realizar sobre la situación en la que se encuentra. Es fácil que aparezcan respuestas de temor, y que se recrudezca la percepción de amenaza para la vida. Podemos observar situaciones de máxima angustia por el hecho de la hospitalización en sí misma y por qué el paciente puede percibir signos de deterioro y enfermedad y pensamientos sobre la muerte. Tampoco se puede obviar un aspecto social nada despreciable: un ingreso hospitalario, supone convivencia con otros pacientes y sus allegados, personas con distintos estilos de vida y culturas, con distintas formas de afrontamiento y con enfermedades que pueden manifestarse con síntomas y expresiones diversas.

La herramienta que supone la comunicación con las peculiaridades enumerada en el aparatado anterior, en el ámbito profesional de enfermería se denomina Relación de Ayuda o Comunicación Terapéutica (Chalifour, 1994). El objeto es que el paciente sufra menos, posea recursos para sentirse mejor y se produzca un cambio en sus actitudes y comportamientos (Cibanal, Arce y Carballal, 2003).

Corona, Rojas, Alvarado, Calderón y Ochoa (2008) en su estudio realizado a pacientes con cáncer hematológico, resaltan la importancia de la atención psicoemocional a estos pacientes, la cual debe proporcionarse de forma continua y señalan que "la atención de calidad y calidez humana otorgada por parte del equipo de enfermería y el ambiente de la unidad de trasplante son factores que pudieron fomentar la mejora del estado emocional de los pacientes".

Fernández-López y Hernández - Mejía (1993) refieren que "lo que importa en la última década del siglo $X X$ es cómo se siente el paciente, y no lo que los médicos pensamos que debería sentir, basados solamente en mediciones clínicas. Éste es un importante avance en la filosofía médica, que está siendo cada vez más aceptado en nuestra profesión".

Para Couceiro (2004), el ser humano se halla en un entorno tecnificado. Especialmente en unidades de críticos, la técnica se ha convertido en un fin, cuando en realidad, es un medio para la consecución de unos fines, que requieren ser pensados y definidos por los que hacen uso de ella. La técnica es, en estos casos, una de las causas generadoras de sufrimiento en estas unidades.

El desarrollo tecnológico en unidades de pacientes críticos, ha vivido toda una época de fascinación y éste ha sido uno de los elementos que más deshumanización y más sufrimiento ha producido en estos sectores hospitalarios (Esteban, Gómez Rubí y De La Cal, citados en Couceiro, 2004).

Debemos analizar la relación del hombre con su dolor y cómo influye de la trama social y cultural en la conducta y valores. Según las condiciones de vida y la concepción del mundo que tengan, los seres humanos se manejan con su dolor o su pena, se apropian de estos a través de sus valores y modelos de comportamiento. El dolor no es solo un estímulo sobre un receptor biológico, sino lo que siente un ser humano con toda la masa de sus sentimientos, su psicología personal, valores y creencias (Le Breton, 1999).

Todo lo expuesto nos hace plantearnos un concepto amplio e integral de la salud y la atención sanitaria. Los profesionales de este ámbito, somos conscientes de la importancia de una atención individualizada que va más allá de la aplicación de tratamientos, técnicas y cuidados orientados a la sintomatología física, prestando cuidados integrales que cubran las necesidades psicosociales de los pacientes a los que atendemos (Gómez Díaz, 2000). 